\title{
Real-Time Measurements of Aft Dome Insulation Erosion on Space Shuttle Reusable Solid Rocket Motor
}

\author{
Bruce McWhorter ${ }^{*}$, Mark Ewing ${ }^{\dagger}$, Kevin Albrechtsen ${ }^{\ddagger}$, Todd Noble ${ }^{\S}$, and Matt Longaker ${ }^{* *}$ \\ ATK Thiokol Propulsion, P.O. Box 707, Brigham City, Utah, 84302
}

\begin{abstract}
Real-time erosion of aft dome internal insulation was measured with internal instrumentation on a static test of a lengthened version of the Space Shuttle Reusable Solid Rocket Motor (RSRM). This effort marks the first time that real-time aft dome insulation erosion (i.e., erosion due to the combined effects of thermochemical ablation and mechanical abrasion) was measured in this kind of large motor static test [designated as Engineering Test Motor number 3 (ETM-3)]. This paper presents data plots of the erosion depth versus time. The data indicates general erosion versus time behavior that is in contrast to what would be expected from earlier analyses. Engineers have long known that the thermal environment in the aft dome is severe and that the resulting aft dome insulation erosion is significant. Models of aft dome erosion involve a two-step process of computational fluid dynamics (CFD) modeling and material ablation modeling. This modeling effort is complex. The timedependent effects are difficult to verify with only prefire and postfire insulation measurements. Nozzle vectoring, slag accumulation, and changing boundary conditions will affect the time dependence of aft dome erosion. Further study of this data and continued measurements on future motors will increase our understanding of the aft dome flow and erosion environment.
\end{abstract}

\section{Introduction}

Large solid rocket motors, with submerged nozzle configurations, can experience severe erosion of the internal aft dome insulation. Engineers working on new aft dome designs desire to understand this high-temperature internal flow environment of the aft dome as well as the insulation thermal/erosion response to this environment. However, this flow environment is complex. It involves the two-phase flow of solid propellant combustion gases and liquid slag $\left(\mathrm{Al}_{2} \mathrm{O}_{3}\right)$. This slag accumulates in the aft dome region in the form of a slag pool, slurry, or dense two-phase gas and droplet cloud. ${ }^{1,2,3,4}$ The medium of the accumulation is not well understood in all solid rocket motors. A growing slag pool will change the gas flow boundaries. Real-time X-ray radiography (RTR) has been used to characterize this aft dome flow in some motors. ${ }^{1}$ The flow pattern and slag accumulation change with motor operation time. Nozzle vectoring can also change this flow environment and the slag accumulation.

The nature of the slag/droplet flow and its time dependency has a direct impact on the heat transfer and resulting insulation erosion in the aft dome. The physics required to calculate insulation erosion is complex. The insulation is eroded by both thermochemical ablation and mechanical abrasion. Time-dependent measurements of aft dome erosion could increase our understanding of how insulation erosion is affected by different flow parameters. The same time-dependent measurements could indirectly increase our understanding of the aft dome time-dependent environment. This paper presents aft dome erosion depths versus time for a lengthened version of the RSRM.

\footnotetext{
* Senior Principal Engineer, Electrical/Ordnance Design, ATK Thiokol Propulsion.

† Senior Principal Engineer, Heat Transfer, ATK Thiokol Propulsion.

¥ Senior Principal Engineer, Insulation Design, ATK Thiokol Propulsion.

$\$$ Manufacturing Engineer, Insulation Design, ATK Thiokol Propulsion.

** Test Transducer Engineer, Test Transducer Development Lab, ATK Thiokol Propulsion.
}

Copyright $(2004$ by ATK Thiokol, an Alliant Techsystems Inc. affiliate.

Published by the American Institute of Aeronautics and Astronautics, Inc., with permission 
When the decision was made to proceed with this instrumentation, planning for a five-segment, as opposed to the usual four-segment, RSRM static test was in progress. This static test was designated as ETM-3. Aft dome erosion versus time for a five-segment motor would be valuable since it was expected to experience higher aft dome erosion than the normal four-segment RSRM. A longer motor generates more propellant combustion gas mass flow through the aft motor segment. This extra mass flux makes harsher the already severe erosion environment. So, having this instrumentation in the ETM-3 static test would provide important time-dependent data.

\section{Background - RSRM Aft Dome Design}

The RSRM aft end geometry comprises a submerged nozzle and aft dome (Fig. 1). Internal insulation is used to protect the inner diameter walls of the aft dome from the extremely hot combustion gases and $\mathrm{Al}_{2} \mathrm{O}_{3}$ slag. The primary insulation in the RSRM aft dome is a carbon fiber-filled ethylene-propylene-diene monomer (CFEPDM). This material has proved to be well suited for this aft dome environment due to its thermal erosion resistance as compared to other rubber materials. A shear ply rubber insulator lies between the case wall and CFEPDM and serves to enhance the structural integrity of the insulation system.

This paper is concerned only with erosion versus time measurements of the aft end of the ETM-3 aft dome (Fig. 2). The data discussed in this paper was measured in a region approximately 10.7 inches forward of the nozzle-tocase joint, referred to as station 3 . This region in the aft end of the dome is exposed to hot propellant gases and slag for the duration of motor operation.

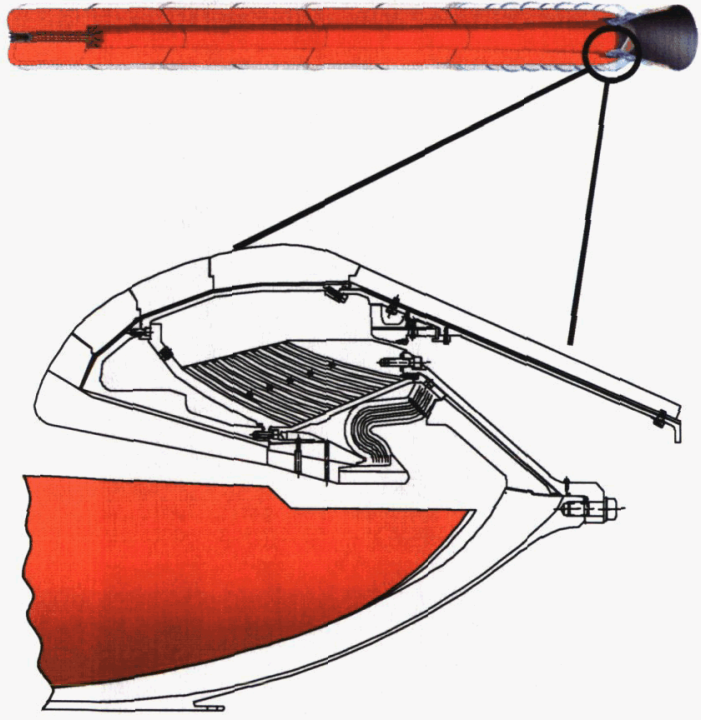

Figure 1 RSRM submerged nozzle and aft dome configuration

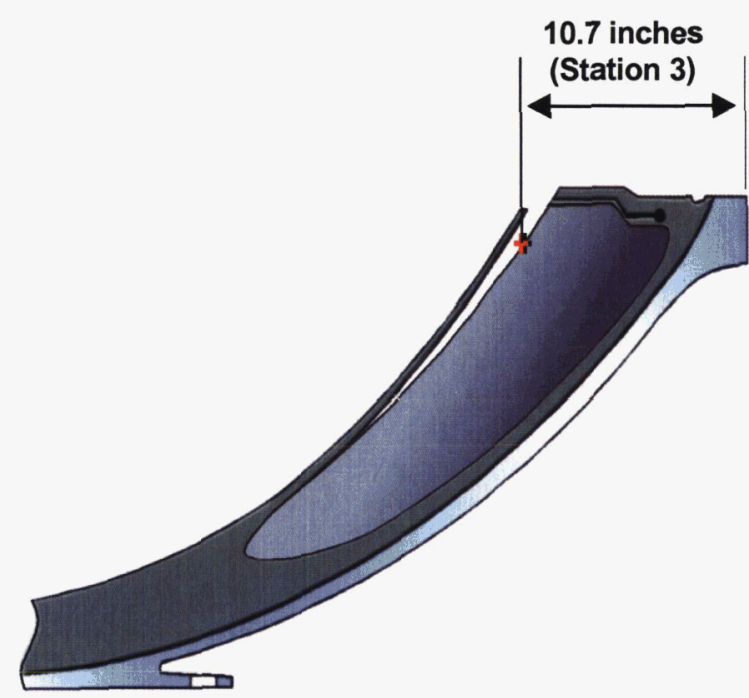

Figure 2 Aft dome station of interest

\section{Ablation Modeling - Overview of Current Understanding and the Need for More Data}

The analyses performed to predict aft dome insulation erosion are extremely complex. Capable investigators have made great strides in modeling the complex two-phase flow environment in the aft dome and the ensuing chemical ablation. The current method is a two-step process of CFD modeling followed by modeling of material decomposition and surface thermochemical ablation. Each step involves modeling of dynamic conditions where not all parameters are well understood and some simplifying assumptions must be made.

The CFD modeling of this environment is particularly challenging. The flow involves two phases: propellant combustion gases and liquid $\mathrm{Al}_{2} \mathrm{O}_{3}$. The physics of $\mathrm{Al}_{2} \mathrm{O}_{3}$ droplet sizes and shapes is complicated. The flow affects how the droplets will coalesce or break apart, which affects trajectories and subsequent aft dome impact and accumulation. It is known that slag impinges on the aft dome insulation and accumulates in the aft dome region. ${ }^{1,2,3,4,5}$ The nature of this slag flow medium is uncertain, and subsequent thermal and chemical boundary conditions are therefore difficult to predict. 
The flow in the aft dome is time dependent since the physical and gas generation boundaries change with time. Figure 3 illustrates approximate RSRM (ETM-3) propellant web profiles at several different motor operation times. The effect of this propellant web burn-back is that the flow boundaries in the aft dome will change with motor operation time. The resulting two-phase flow velocities, mass flux, and heat transfer coefficients change during motor operation time. Velocities and slag impingement flux increase during the last half of motor operation. ${ }^{1,5,6}$ Because of this time dependency, previous studies estimate that the majority of insulation erosion occurs during the last half of motor operation. 5,7

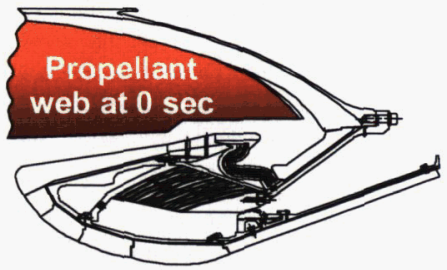

Minimal gas velocity and slag impingement

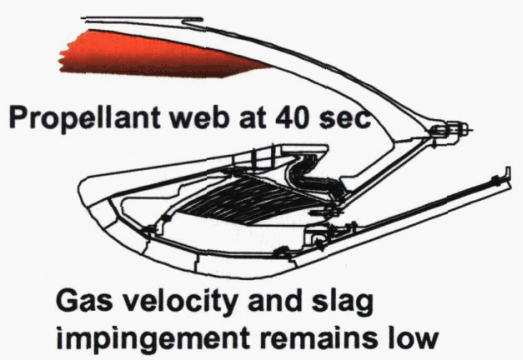

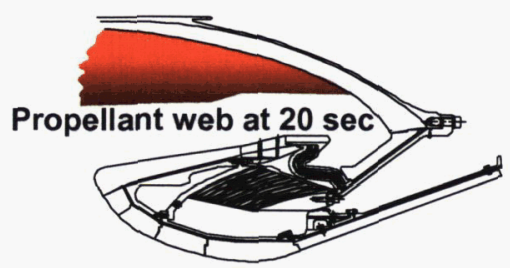

Gas velocity and slag impingement remains low

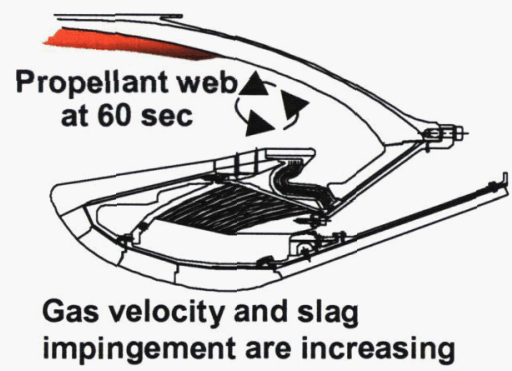

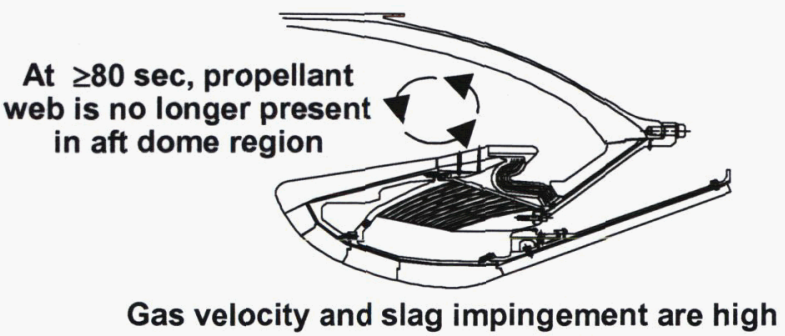

Figure 3 Axisymmetric cross sections of aft dome propellant web showing changing flow boundaries with time

The science of thermal decomposition and chemical ablation has been thoroughly studied by many investigators. Most of the physical models are based on the classic work of Moyer and Rindal ${ }^{8}$ and Kendall, et al. ${ }^{9}$ These models account for in-depth thermal penetration, material decomposition and char formation, pyrolysis gas generation, and mass flow and energy exchange with the porous char. Surface thermochemical ablation associated with the gaseous phase of propellant combustion products are also modeled. Typically, the models indicate that the penetrating char front progresses through the insulation with a steep temperature gradient (Fig. 4). Below this char front, the insulation is nearly at its initial temperature - roughly room temperature. As the char front approaches, the temperature rises sharply. Within the char, the temperature gradient remains steep as the temperature rises to the very high temperature $\left(\sim 4000^{\circ} \mathrm{F}\right)$ of the ablating surface. The char layer is thin when ablation rates are high. 
Chemical ablation analysis is complex, and not all of the conditions can be modeled. Current methods use only the gas phase to model chemical ablation. Models based on these theoretical calculations, using only the gas phase, under-predict erosion in the RSRM aft dome. Undoubtedly, there is enhancement to the heat transfer by the two-phase flow. It is also likely that the $\mathrm{Al}_{2} \mathrm{O}_{3}$ liquid phase affects chemical ablation. Furthermore, surface erosion is likely occurring due to mechanical abrasion of the charred surface by slag impingement. The high-temperature char material properties required to model this kind of mechanical abrasion of the char layer are not known.

Because of these uncertainties, aft dome insulation erosion predictions have relied on empirical methods and static test data. Postfire measurements show that the RSRM aft dome is highly eroded - especially at the aft end of the dome (Fig. 5) where slag impingement is predicted to be severe. ${ }^{5}$ The RSRM design ensures that thermal safety factors are met with the demonstrated use of an adequate thickness of CFEPDM. ${ }^{10}$ However, if a design or material change is desired, predictions of insulation erosion are needed. Because models based on theoretical calculations tend to under-predict erosion, empirical methods are employed. Naturally, these empirical methods require test data for confirmation. Historically, this data has been obtained from subscale as well as full-scale tests. The data is used to empirically establish multiplication factors to the predicted heat transfer coefficients. With these factors, a final (end of motor operation) total insulation erosion depth can be predicted. These empirical models are useful and can be accurate for prediction of a total postfire erosion depth.

Static tests, however, are expensive. Proposed design changes and insulation material changes have demanded that our knowledge of aft dome erosion be greatly improved. More accurate thermal erosion models would enable quicker design changes and material downselections with fewer static tests. These models would be complex, involving the time-dependent effects of the gas and condensed phases on insulation erosion.

These complex models will require data for verification. Since the flow environment varies with time, erosion data versus time is needed. A comparison of erosion versus time with CFD flow parameters versus time might lead to an understanding of how these parameters drive insulation erosion. This time-dependent data would be a direct anchor for thermal erosion models and might also offer insight into how flow parameters change with time.

\section{Measurement Method}

A simple measurement method for obtaining erosion depth versus time was implemented. The method is to place six thermocouples at successively deeper depths in the aft dome insulation (Fig 6). The thermocouples are installed at station 3 during manufacturing, and their depth in the insulation is measured. During motor operation, the temperature versus time of each thermocouple is measured. Acting as an event indicator, each temperature measurement registers the time of a sharp temperature increase, indicating the arrival time of the char front. Correlating the depth of each thermocouple to its char front arrival time provides a data point. These points, when plotted as depth versus time, give a good indication of the erosion depth versus time at station 3 . (The char depth 
versus time can be estimated to be erosion depth versus time since it is expected that the char layer is relatively thin in this high erosion rate environment.) ${ }^{7}$

To minimize a possible effect of the thermocouples having a compounding effect on erosion rate, each thermocouple within the array is circumferentially and sequentially staggered. Figure 6 also shows this configuration.

The array of six thermocouples (Fig. 6) is installed at four different circumferential locations (24 total thermocouples). Multiple circumferential locations can help discern circumferential variations in erosion rate, which are known to exist from postfire measurements and are assumed to be caused by nozzle vectoring events. Multiple arrays also increase the probability that measurements can be made in the event of individual thermocouple failures. Although these thermocouples are structurally robust, lead wire connection failures can occur. The thermocouples are installed early in the manufacturing process, leaving much time for a weak connection to fail.

In order for this simple instrumentation technique to be effective, accurate thermocouple depths must be known. Only then can the time of the sharp temperature rise be correlated to an accurate depth. The thermocouples are installed during installation of the CFEPDM in the aft dome. After the CFEPDM is laid in place, it undergoes a curing process. During cure, the CFEPDM layup thickness decreases ("de-bulks"). This de-bulk event changes the depths of the thermocouples to unknown depths. These depths need to be measured by nondestructive means. Experience had already shown that X-ray methods cannot measure accurate depths. Ultrasonic methods, however, can be used if special features are added to each thermocouple so that an ultrasound signal can be reflected.

Testing was done at ATK Thiokol Propulsion to develop a thermocouple configuration that would reflect an ultrasound signal. ${ }^{11}$ Test results proved that concentrically added thermo-couple wire insulation (Teflon ${ }^{\circledR}$ and Viton ${ }^{\circledR}$ ) materials enables the

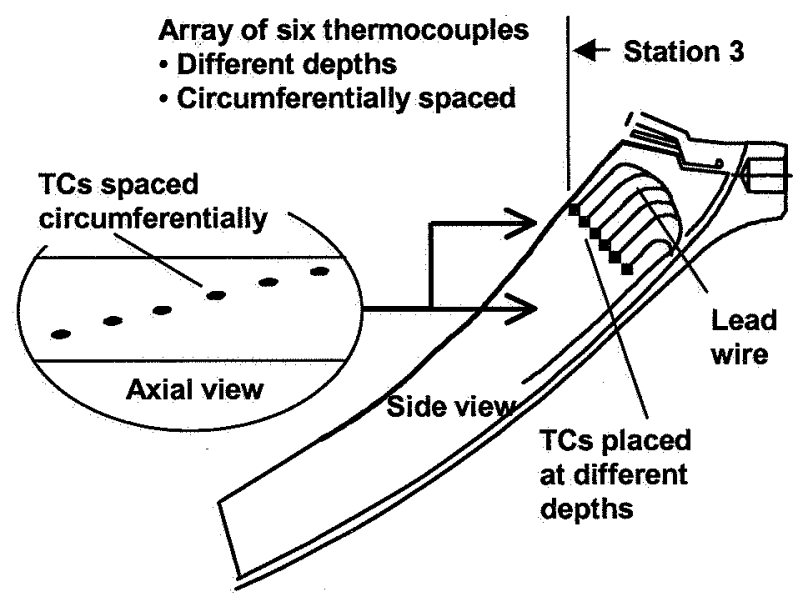
thermocouples to reflect this ultrasound signal. The final Figure 6 Schematic of thermocouple (TC) array thermocouple wire thickness, with this insulation, is approximately 0.1 inch. A manufacturing aft dome test article, with CFEPDM and thermocouples installed, was used to test this technique. The thermocouple array spanned a distance of approximately 3.5 inches in the tested configuration as shown in Fig. 6. The depth of each thermocouple was measured by the ultrasonic method. Dissection of the test article showed that the ultrasonic determined depth of each thermocouple was within $+/-0.1$ inch of the actual (dissected) thermocouple depth. In most cases, the ultrasonic determined depths were more accurate than $+/-0.1 \mathrm{inch}$. The use of ultrasonic measurements, post insulation cure, allows engineers to determine accurate depths of the thermocouples.

\section{ETM-3 Aft Dome Measured Thermocouple Data}

During the ETM-3 firing, each thermocouple did measure a sharp increase in temperature. Figure 7 presents the typical response of a thermocouple array. The sharp increase in temperature represents the arrival of the char front through the material as it reached the depth of the thermocouple location. The char layer is expected to be thin relative to the erosion depth. So, the char depth versus time can be estimated to be erosion depth versus time. 


\section{Aft Dome TC Temperature Responses}

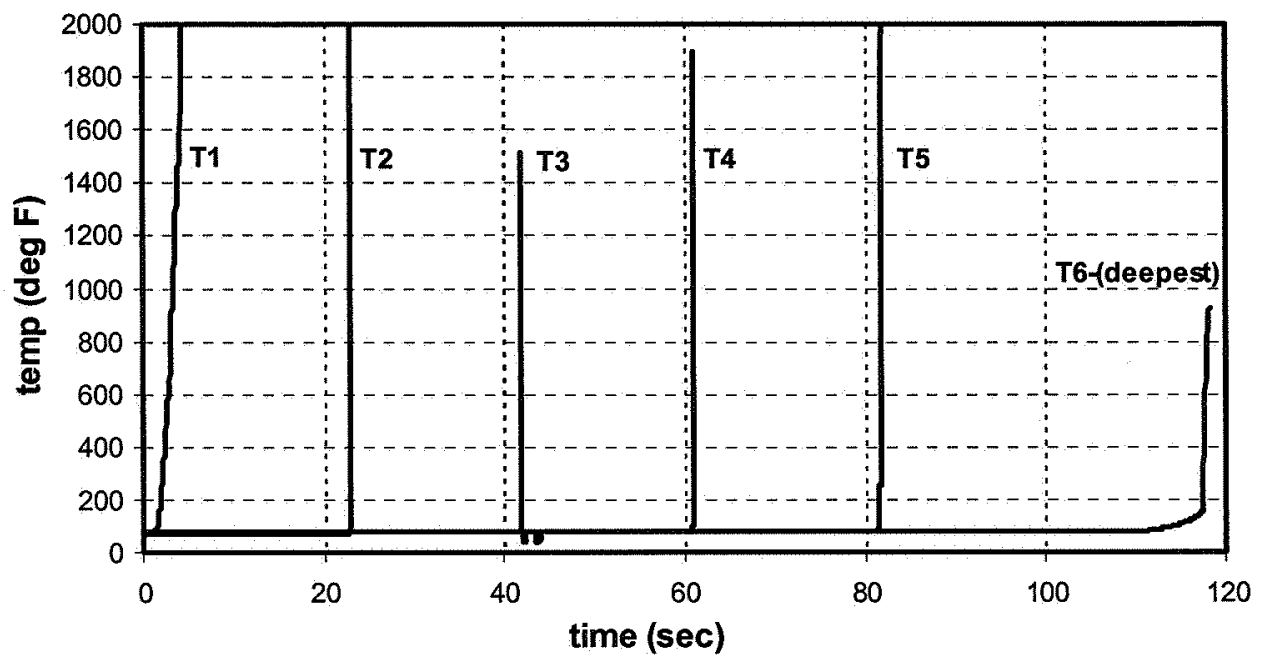

Figure 7 Thermocouple responses at $31^{\circ}$ (station 3)

The data was collected and organized to plot thermocouple positions (depths) versus the measured times of char (erosion) front arrival. Figure 8 presents the erosion depth versus time for the four circumferential locations measured in the aft dome. As stated earlier, the axial location for these measurements is station $3(\sim 10.7$ inches forward of the nozzle-to-case joint as shown in Fig. 2). The last point for each of the four plots was taken from hand-measured postfire insulation thickness data. So, the instrumented (real-time) data is anchored to postfire measured data representing the time and erosion depth at the end of motor operation.

Some general observations about erosion rate are made from this data. Observe the noted erosion rates (and slope changes) in the plots of Fig. 8. The general trend is for the erosion to proceed at a high rate, with some short duration changes, for the first 90 seconds. All thermocouples show a slight decrease in erosion rate starting at roughly 90 to 100 seconds. There is circumferential variation as noted by comparison of the four circumferential measurement locations. The two circumferential locations $\left(121^{\circ}\right.$ and $211^{\circ}$ ) on the top half of the motor (this motor was fired horizontally) appear to start their decline in erosion rate a little early - roughly at 90 seconds. On the other hand, the two circumferential locations $\left(31^{\circ}\right.$ and $\left.301^{\circ}\right)$ on the bottom half of the motor appear to start their decline at 100 seconds. Also, the $301^{\circ}$ location shows a relatively faster erosion rate for the first 40 seconds followed by a rate that is more comparable to the other locations. Comparing this data to the results of three-dimensional CFD models, that include the effects of gravity on horizontal gas and $\mathrm{Al}_{2} \mathrm{O}_{3}$ flow, could provide clues as to how slag (or other parameters) might affect the circumferential erosion pattern.

Some correlation exists between nozzle duty cycle and the data of Fig. 8. Figure 9 shows the nozzle duty cycle used on ETM-3. Shortly after 20 seconds, there is significant duty cycle change. From 22 seconds until 58 seconds, the nozzle yaws towards $270^{\circ}$ thereby exposing the $270^{\circ}$ aft dome region to the effects of the bore flow. During this time, the locations at $301^{\circ}$ and $211^{\circ}$ show an increase in erosion rate whereas the location at $121^{\circ}$ shows a decrease. At 60 seconds, there is another significant change in nozzle position that exposes the $90^{\circ}$ aft dome region to possible effects of bore flow. The erosion rate of the $121^{\circ}$ location increases at this time. One data point from the $301^{\circ}$ location is missing (one thermocouple malfunctioned) during this time, so its real response is uncertain. Threedimensional CFD modeling, accounting for adjustments in nozzle position and the resulting changes in flow as a function of circumference, might lend evidence to the specific flow parameters that correlate to these shifts in erosion rate. 


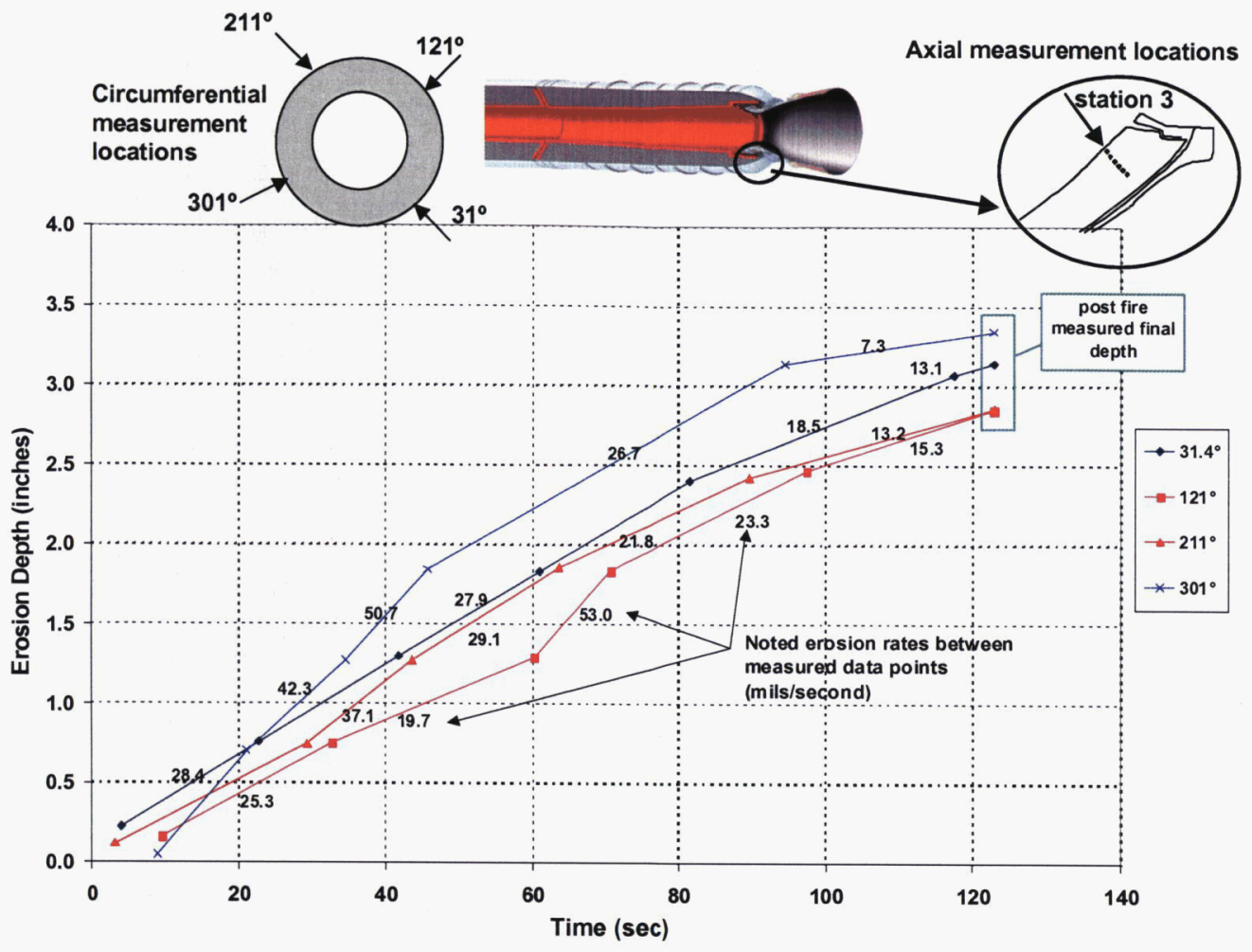

Figure 8 Ablation indicator thermocouple results

The most interesting observation is in strong contrast to what would be expected from earlier analyses. CFD studies $^{5,6}$ and erosion predictions ${ }^{7}$ indicate that the rates should increase with time - especially at 50 to 70 seconds. Figure 10 presents results drawn from an early analysis ${ }^{7}$ and was based from CFD results with no time-dependent data available to confirm the prediction. These studies had concluded that most insulation erosion should occur during the last half of motor operation since: 1) the gas flow is directed forward and away from the aft dome insulation early in operation, and 2) later in motor operation the aft dome volume (Fig. 3) is opened and higher gas

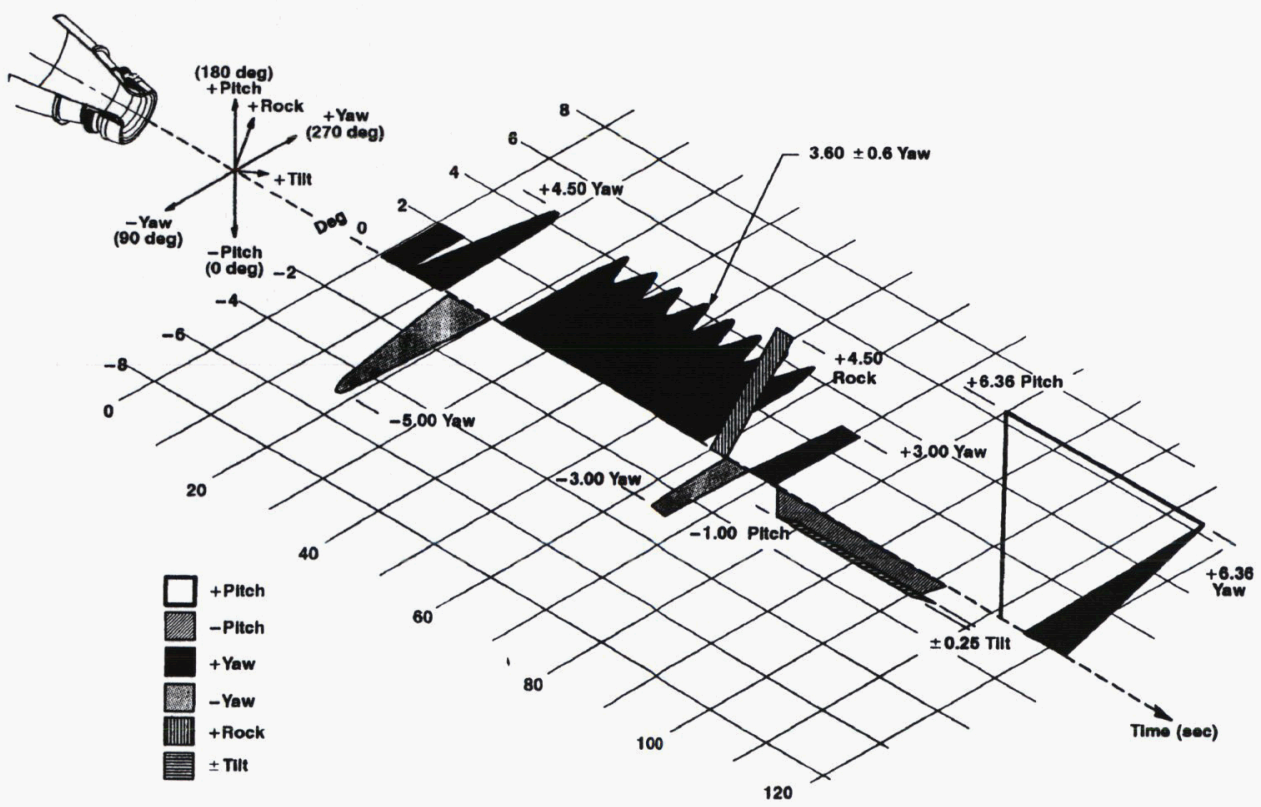

Figure 9 ETM-3 nozzle duty cycle 


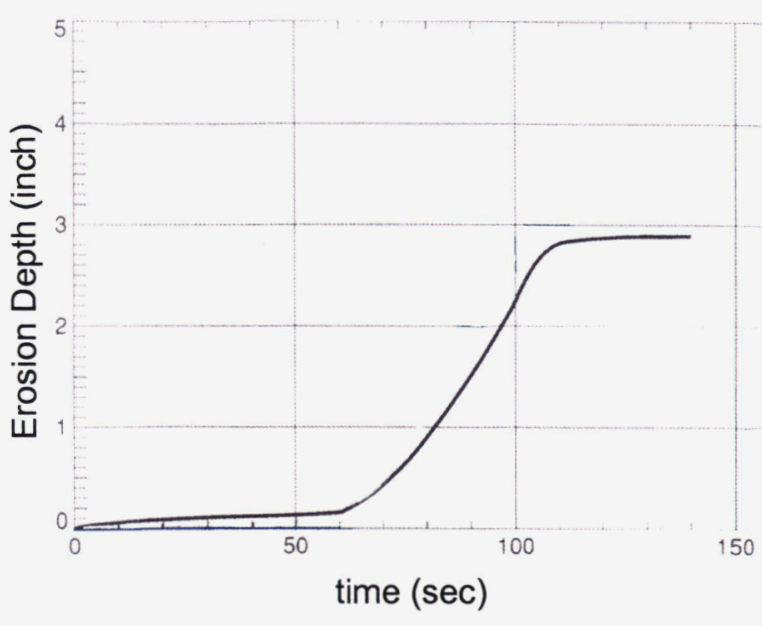

Figure 10 Example prediction ${ }^{7}$ of aft dome erosion near station 3 for a four-segment RSRM configuration velocities with slag impingement ${ }^{5}$ are occurring. The data in Fig. 8 shows that the rates for each location are relatively fast early in motor operation, do not increase after 50 seconds (not including the short duration rate changes due to duty cycle), and are generally more constant than the old prediction shown in Fig. 10. Obviously, other physical parameters are playing a role in the aft dome erosion environment.

\section{Future Work}

The intention of this paper is to present this aft dome erosion data. Future research using experimentation and complex CFD two-phase flow modeling followed by improved thermal erosion modeling will be required to improve prediction capabilities. High-temperature material properties will be needed. More complex data (gas velocities, slag mass flux, etc.) gathered by more elaborate means, may also be needed. This model improvement effort will be complicated but valued for future design programs.

Two more RSRM static tests are scheduled to use aft dome insulation thermocouples to measure erosion depth versus time. These test motors are planned to be the standard four-segment RSRMs. This additional data, in comparison to the data presented here, could offer clues to the flow/erosion environment and will provide motor-tomotor variation data.

Subscale testing with a 24-inch-diameter test motor is also providing data toward the goal of better understanding aft dome insulation erosion. This motor is easily instrumented, and methods to use RTR on its aft dome are being explored. It is desired to configure this motor so that it experiences aft dome slag accumulation and therefore provide additional CFEPDM erosion rate data.

Improvements to CFD and erosion modeling with study of this data could provide correlations to the flow parameters that affect erosion. Better estimates of the nature of the flow medium (slag) in the aft dome could be obtained.

\section{Conclusion}

This paper presents measurements of aft dome insulation erosion versus time. The data was obtained from a static test of a lengthened RSRM (ETM-3). The data presented reveals some correlation to nozzle vectoring events as well as effects of firing the motor in a horizontal position. However, the data indicates general erosion versus time behavior that is in contrast to what would be expected from earlier analyses. Prediction improvements will require complex CFD and improved thermal erosion modeling. Test data will be needed to verify these models. The type of large motor internal motor data gathered and presented in this paper is a start.

\section{Acknowledgments}

To measure this data on a full-scale test motor required a great team effort. Enormous work and input by many professionals was completed to instrument and fire the ETM-3 test motor. The authors thank all personnel of Test Operations, the Test Transducer Development Lab, the Insulation Work Center, Propellant/Liner/Insulation Structures, Heat Transfer, and Electrical/Ordnance Design. Special thanks goes to many of the professionals working in these departments including, but not limited to, Lance Krebs, Lloyd Johnson, Alan Godfrey, Todd Earnest, Larry Allred, Norm Eddy, Kevin Rees, Jane Johnson, Mark Berger, Pat Downey, Lonny Veater, Howard Healey, and Danny "Tucker" Wettstein.

Personal conversations with other experts, inside and outside of ATK Thiokol Propulsion, have helped the authors expand their perspectives on the possible explanations for the measured data. The authors thank Bob Morstadt, Mark Salita, Louie Clayton, Andy Eaton, and Herold Whitesides.

The authors thank the Marshall Space Flight Center for encouraging and funding the ETM-3 static test and allowing this data to be measured. The authors thank Tom Williams for first suggesting and encouraging instrumentation of the aft dome, which was the initiative for this aft dome instrumentation effort. 


\section{References}

${ }^{1}$ Salita, M., "Predicted Slag Deposition Histories in Eight Solid Rocket Motors Using the CFD Model 'EVT'," AIAA 952728, 10-12 July 1995.

${ }^{2}$ Whitesides, H. R., Purinton, D. C., "Effects of Slag Ejection on Solid Rocket Motor Performance," AIAA 95-2724, 10-12 July 1995.

${ }^{3}$ Schorr, A. A., Speas, K. J., "Reusable Solid Rocket Motor (RSRM) Pressure Perturbation Characterization An Overview," AIAA 95-2722, 10-12 July 1995.

${ }^{4}$ Hopson, C., "Space Shuttle Solid Rocket Motor Slag Expulsion Mechanisms," AlAA 95-2725, 10-12 July 1995.

${ }^{5}$ Whitesides, H. R., Dill, R. A., Purinton, D. C., "Application of Two-Phase CFD Analysis to the Evaluation of Asbestos-Free Insulation in the RSRM," AIAA 97-2861, 6-7 July 1997.

${ }^{6}$ Ahmad, R. A., Morstadt, R. A, "Gas Dynamics and Slag Analysis of the ETM-3 Nozzle Flow Field," ATK Thiokol Propulsion Report TWR-74422 Rev. B, 23 September 2002.

${ }^{7}$ McWhorter, B. B., "Thermal/Ablation Analysis of the FSM-5 Aft Dome Asbestos-Free Insulation," ATK Thiokol Propulsion Report TWR-66464, 18 January 1995.

${ }^{8}$ Moyer, C. B. and Rindal, R. A., "An Analysis of the Coupled Chemically Reacting Boundary Layer and Charring Ablative, Part II, Finite Difference Solution for the In-Depth Response of Charring Materials Considering Surface Chemical and Energy Balances," Prepared for NASA contract NAS 9-4599 by ITEK Corporation, Vidya Division, 1968.

${ }^{9}$ Kendall, R. M., Rindal, R. A., Bartlett, E. P., “A Multicomponent Boundary Layer Chemically Coupled to an Ablating Surface," AIAA Journal, Vol. 5, No. 6, June 1967.

${ }^{10}$ Eddy, N., "RSRM Internal Insulation and Igniter Insulation Design Summary," ATK Thiokol Propulsion Report TWR18133, 2 December 2002.

${ }^{11}$ Earnest, T. E., "Final Report for ETP-1979, Aft Dome PSA", ATK Thiokol Propulsion Report TWR-74384, 22 October 2001. 